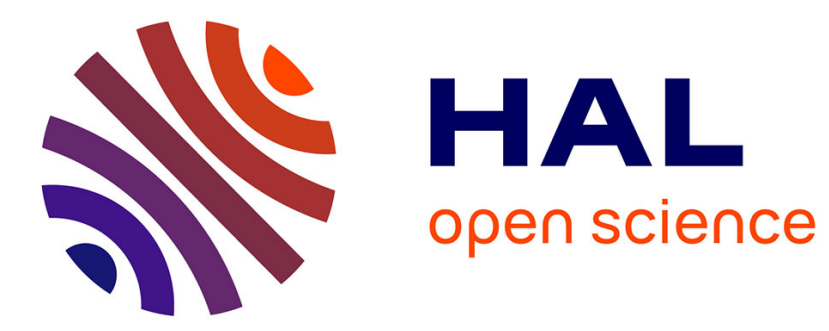

\title{
Environmental taxation: Pigouvian or Leviathan?
} Isabelle Cadoret, Emma Galli, Fabio Padovano

\section{To cite this version:}

Isabelle Cadoret, Emma Galli, Fabio Padovano. Environmental taxation: Pigouvian or Leviathan?. Journal of Industrial and Business Economics = Economia e politica industriale, 2021, 48 (1), pp.37-51. 10.1007/s40812-020-00149-8 . hal-02544523

HAL Id: hal-02544523

https://hal-univ-rennes1.archives-ouvertes.fr/hal-02544523

Submitted on 16 Apr 2020

HAL is a multi-disciplinary open access archive for the deposit and dissemination of scientific research documents, whether they are published or not. The documents may come from teaching and research institutions in France or abroad, or from public or private research centers.
L'archive ouverte pluridisciplinaire HAL, est destinée au dépôt et à la diffusion de documents scientifiques de niveau recherche, publiés ou non, émanant des établissements d'enseignement et de recherche français ou étrangers, des laboratoires publics ou privés. 


\section{Environmental taxation: Pigouvian or Leviathan?}

2 Isabelle Cadoret ${ }^{1} \cdot$ Emma Galli $^{2}$ - Fabio Padovano ${ }^{1,3}$

3

\section{Abstract}

6 This paper empirically examines which type of taxes are environmental taxes, by 7 analyzing how governments actually use them. The theoretical literature is polarized between two alternative interpretations of environmental taxes: the Pigouvian and the Leviathan hypotheses, each leading to alternative testable hypotheses. We test them on a sample where the analysts' discretionary evaluations are minimal, the EU-28 countries that committed themselves to correcting a negative environmental externality, the greenhouse gas emissions, by 2020. The estimates lend support to the strict Pigouvian hypothesis, while the Leviathan hypothesis appears less consistent with the data.

Keywords Environmental taxes · Pigouvian taxation · Leviathan government $\cdot$ GHG reduction $\cdot$ Arellano-Bond GMM

JEL Classification Q28 · H54 · H87 · D72 · D73 · D78

\section{Introduction}

What type of taxes are, in fact, environmental taxes (henceafter, ET)? For what purposes governments actually use them, and how efficient are they in achieving such goals?

Paper presented at the AISRe 2019 conference at the GSSI L'Aquila, EPCS 2017 conference in Budapest, EALE 2016 conference in Bologna, SIEP 2016 conference in Lecce and the TEPP Conference at La Réunion. We thank the participants to these conferences, as well as Nicolas Gavoille, Benoit Le-Maux and Yvon Rocaboy for helpful comments on previous versions of this paper. The usual caveat applies.

$\square$ Emma Galli

emma.galli@uniroma1.it

1 Univ Rennes, CNRS, Condorcet Center for Political Economy, CREM UMR6211, 35000 Rennes, France

2 Department of Social and Economic Sciences, Sapienza University of Rome, Rome, Italy

3 DSP, Università Roma Tre, Rome, Italy 
The theoretical literature is polarized between two alternative answers to these questions, which can rationalize why governments resort to ET. The classical Pigouvian interpretation holds that ET suffice to internalize and correct negative environmental externalities, regardless of how their revenues are being spent (Baumol and Oates 1988). The alternative interpretation views ET just like any other tax, with the notable exception that they are the least unpopular among all fiscal levies, because of the citizens' favorable outlook on the protection of the environment (EU Commission 2014). Leviathan governments, aiming at maximizing tax revenues at the lowest political cost, exploit this feature and resort to ET relatively more, irrespective of their efficiency at achieving environmental goals (Kirchgassner and Schneider 2003). These hypotheses reflect two opposite visions of government: a benevolent one, stemming from the welfare economics tradition, and a utility-maximizing one, associated with the public choice school.

This paper empirically analyzes how governments actually use ET to verify which of these two alternative theoretical interpretations best represents the reality of environmental fiscal policy. To this end we consider the sample of the $28 \mathrm{EU}$ countries over the period 2005-2017 that, within the Lisbon agenda, in 2009 have formally decided to commit themselves to attain a specific environmental protection target: the reduction of Green House Gases (henceafter, GHG). Empirically, we use data on Greenhouse gas emissions in Effort Sharing Decision (ESD) sectors concerned by the target ${ }^{1}$.

Two features make this sample especially suitable for this type of analysis: first, GHG reduction is a clearly measurable objective; ${ }^{2}$ second, the countries in the sample have chosen their reduction target themselves. ${ }^{3}$ Both features reduce to a strict minimum the analysts' discretion in the evaluation of the governments' use of ET. ${ }^{4}$ Such an attribute is quite hard to find in the rest of the literature and it greatly eases the task of identifying which theory best represents the way governments actually use ET.

The focus on GHG as pollutant calls into question the role of the heterogenous firms, both in terms of technology adopted and of size of production, which are one of the major (albeit not the only) sources of this type of emissions. As our

1FL01 1 Data are available since 2005.

2FL01 ${ }^{2}$ Article 2.1 of decision 406/2009 defines the GHG emissions as “...the emission of carbon dioxide 2FL02 $\left(\mathrm{CO}_{2}\right)$, methane $\left(\mathrm{CH}_{4}\right)$, nitrous oxide $\left(\mathrm{N}_{2} \mathrm{O}\right)$, hydrofluorocarbons (HFCs), perfluorocarbons (PFCs) and 2FL03 sulphur hexafluoride $\left(\mathrm{SF}_{6}\right),[\ldots]$ expressed in terms of tons of carbon dioxide equivalent".

3FL01 3 Specifically, the EU member states' targets are given by the EU Effort Sharing Decision where "Mem3FL02 ber States' reduction efforts should be based on the principle of solidarity between Member States [...] taking into account the relative per capita GDP of Member States". Furthermore, the national 2020 targets apply to non-Exchange Trade System emissions, a crucial fact, since it allows analyzing the impact of ET in reducing a type of emissions and in sectors where an important policy instrument, such as ETS, do not operate (preliminary n. 6 of decision 406/2009).

4FL01 4 Decision 406/2009 of the EU Parliament and Council of the EU commits the EU member countries 4FL02 collectively to reduce GHG to $70 \%$ of their 1990 levels by the year 2020. In addition to this EU wide tar${ }_{4 \mathrm{FL} 03}$ get, the Decision sets also country-specific targets, to account for the economic and environmental start4FL05 ing point situations of each country, especially those of the former Eastern European nations. (Annexe II to Decision 4006/2009). 


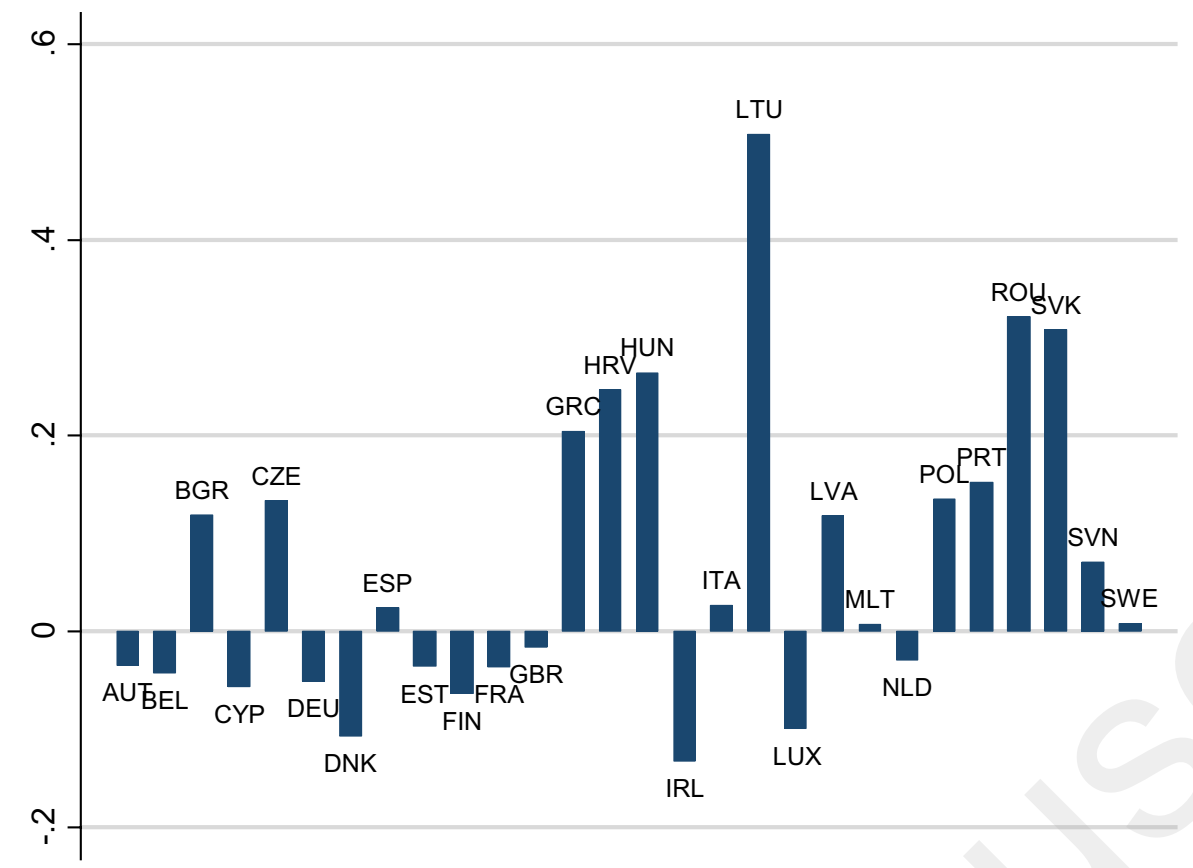

AUT: Austria, BEL: Belgium, BGR: Bulgaria, CYP: Cyprus, CZE: Czech Republic, DNK : Denmark, EST : Estonia, FIN : Finland, FRA: France, DEU: Germany, GRC: Greece, HUN: Hungary, IRL: Ireland, ITA: Italy, LVA: Latvia, LTU : Lithuania, LUX: Luxembourg, MLT :Malta, NLD : Netherlands, POL : Poland, PRT :Portugal, ROU: Romania, SVK: Slovakia, SVN: Slovenia, ESP: Spain, SWE: Sweden, GBR: United Kingdom

Fig. 1 Relative distance from country specific targets for GHG emissions set by Decision n. 406/2009 mean over the period 2005-2017)

analysis is conducted at the country level, we refer to the average environmental friendliness of the technology adopted by the industrial sector of the country.

Our empirical strategy consists in successively testing the empirical restrictions that theory associates with the two alternative interpretations of ET. To verify the Pigouvian hypothesis we compare the intensity with which each country has resorted to ET with the degree of success in achieving the GHG reduction target; a positive correlation between the country's distance from the target and its resort to ET confirms the hypothesis that ET are adopted to (and effective at) correcting the negative environmental externality. Conversely, the Leviathan hypothesis, which basically states that governments set taxes just so to maximize revenues, disregarding the environmental goals of ET, is verified if ET revenues are positively correlated with redistributive, vote buying expenditures items, rather than with public good type of programs.

This type of analysis faces two fundamental difficulties, which the literature has failed to address so far. The first is that the distance from the environmental target can be either negative or positive. As Fig. 1 shows, countries can either fall short of their target, and be therefore supposed to intensify their environmental policies; or they can go beyond their target and might then in principle relax their fiscal efforts aimed at reducing GHG emissions. The negative and positive values that the target variable may assume of course affect the interpretation of the estimated coefficients and complicates the analysis. We address this problem by distinguishing between countries with a positive difference with respect to the target, i.e., those that have already achieved it or even done better, 
from those with a negative difference, i.e., those which have still to attain their target. These two sets of countries are illustrated in Fig. 1.

The second problem is the choice of the proper fiscal indicator to measure the effect of ET on the GHG target. The theoretical literature is not univocal in this respect. Pigouvian models (Baumol and Oates 1988; Sandmo 2010) advise using the effective marginal ET rate as the policy choice variable, as a measure of the disincentive effect to polluting that taxation engenders. Revenue-based measures of fiscal effort, such as the ratio of ET revenues over total tax revenues, seem instead more appropriate for the Leviathan hypothesis, as they reveal the degree to which the government acts in a revenue maximizing way in environmental policy (Schöb 2003). In addition, the ET's efficiency at correcting the externalitya point to be verified in the analysis-also affects the choice of either the ratebased or the revenue-based indicator of the government's effort at reducing the externality. If governments actually use ET in a Pigouvian way and these taxes are effective at reducing GHG emissions, we should observe in those countries higher than average ET rates but lower than average ET revenues, since the high tax rates reduced the externality and hence the revenue source. Yet, if ETs were inefficient at correcting the externality and governments still acted in a Pigouvian way, the revenue source would still exist, so that both rates and revenues should be higher than average. To sort out this potentially serious problem, we estimate the model using proxies for both ET rates and revenues. Indeed, the correlation coefficient between the two indicators is $r=0.16$, low enough to legitimize the use of both of them as alternatives in our analysis. Figures 2 and 3 illustrate the average values of these two variables in the countries of our sample.

As the tested hypotheses refer to two alternatives views of government, we examine the politico-institutional transmission mechanisms between the resort to environmental fiscal means and the attainment of environmental goals - an issue understudied so far (Kirchgassner and Schneider 2003; Cadoret and Padovano 2016). In a Pigouvian world the efficiency of government is the only conditioning factor to the attainment of the policy goal; in a Leviathan world, measures of the rule of law limit the discretionary action of the government, which should instead be sensitive to the demands of special interest groups. We therefore introduce in our empirical specification proxies for the stringency of environmental regulations and for lobbying activity.

The rest of the paper is organized as follows. Section 2 illustrates the empirical strategy, the dataset and the specification of the model. The results of the estimates are presented and discussed in Sect. 3. Section 4 summarizes the conclusions of the analysis.

\section{Empirics}

\subsection{Empirical strategy}

Bringing the two theoretical hypotheses to the data first implies the choice of the dependent variables. These in turn will be regressed, as discussed in Sect. 2.2, on 


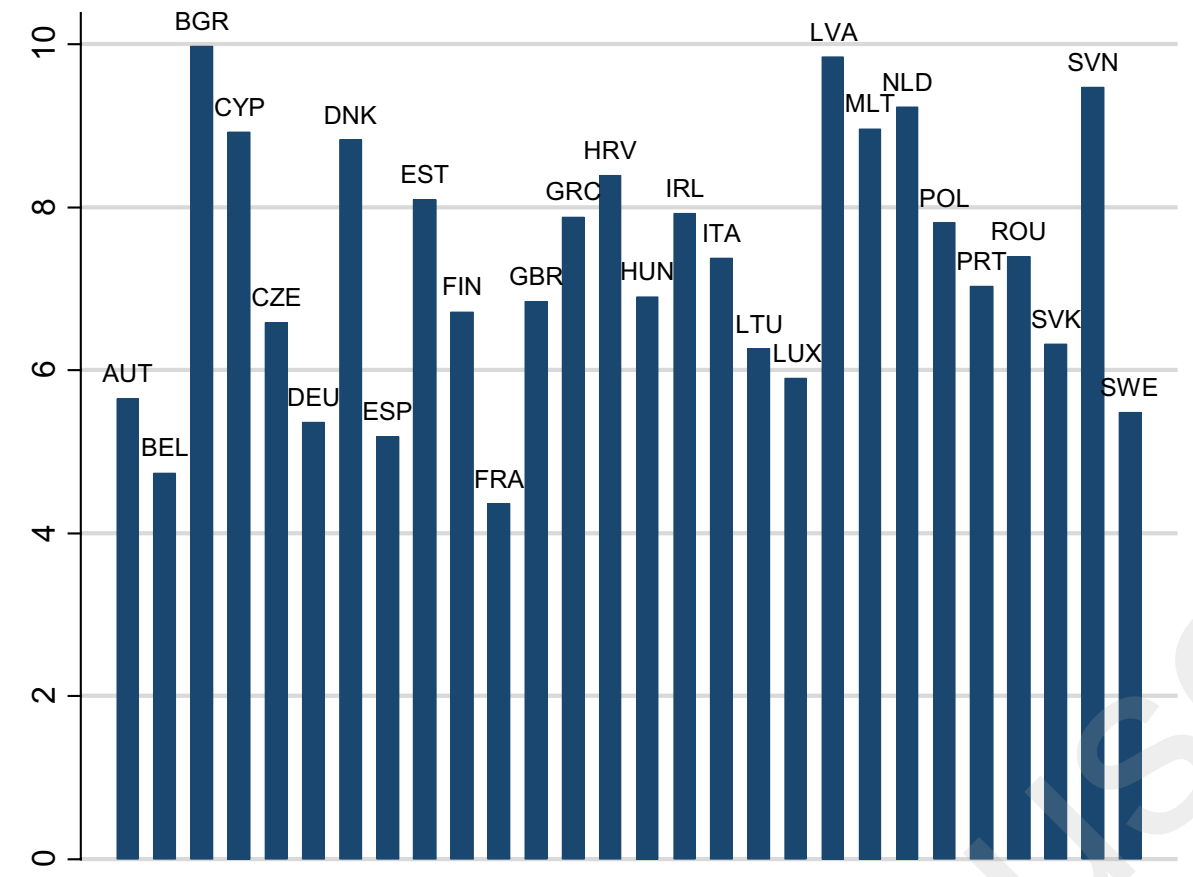

AUT: Austria, BEL: Belgium, BGR: Bulgaria, CYP: Cyprus, CZE: Czech Republic, DNK : Denmark, EST : Estonia, FIN : Finland, FRA: France, DEU: Germany, GRC: Greece, HUN: Hungary, IRL: Ireland, ITA: Italy, LVA: Latvia, LTU : Lithuania, LUX: Luxembourg, MLT :Malta, NLD : Netherlands, POL : Poland, PRT :Portugal, ROU: Romania, SVK: Slovakia, SVN: Slovenia, ESP: Spain, SWE: Sweden, GBR: United Kingdom

Fig. 2 Total environmental taxes as a percentage of total revenues from taxes and social contributions (mean over the period 2005-2017)

the main variables of interest related to each hypothesis plus three sets of controls: (1) the economic variables $\mathbf{X}$; (2) the energy characteristics and environmental pol-AQ1 icy variables $\mathbf{W}$; (3) the politico-institutional variables $\mathbf{Z}$.

To test the Pigouvian interpretation we select relative the difference between the country's GHG emissions target and the observed emissions, named GHG_DIFF, as the endogenous variable (see "Appendix"). It measures the relative distance separating the country from the target assigned by Decision 406/2009-Annexe II. When necessary, this variable is separated in two groups, one including the countries that are doing better than their target (usually, the Eastern European ones) and have thus a positive difference; the other with the countries that are underscoring their specific target (mainly the Western Europeans) and show a negative difference. The specification of the empirical model is as follows:

$$
\begin{aligned}
G H G_{-} D I F F_{i t}= & \alpha_{1} G H G_{-} D I F F_{i t-1}+\beta_{1 R} \mathbf{E T} \_\mathbf{R E V} \mathbf{V}_{\mathrm{it}}+\beta_{1 T} \mathbf{E T} \_\mathbf{R A T E} \mathbf{i t}_{\mathrm{it}} \\
& +\gamma_{1} \mathbf{X}_{i t}+\delta_{1} \mathbf{W}_{i t}+\theta_{1} \mathbf{Z}_{i t}+\varphi_{i}+\varepsilon_{i t}
\end{aligned}
$$

where $i$ identifies the country and $t$ the year and $\varphi$ are the country fixed effects. Since the attainment of the GHG target is progressive over time, the equation includes the lagged dependent variable; it is estimated dynamically via Arellano-Bond GMM estimator with robust standard errors, taking into account the potential endogeneity problem with ET: this may arise because proximity to the GHG target may condition countries' resort to ET, but at the same time the use of ET (if effective) may affect the countries' distance from the target. 


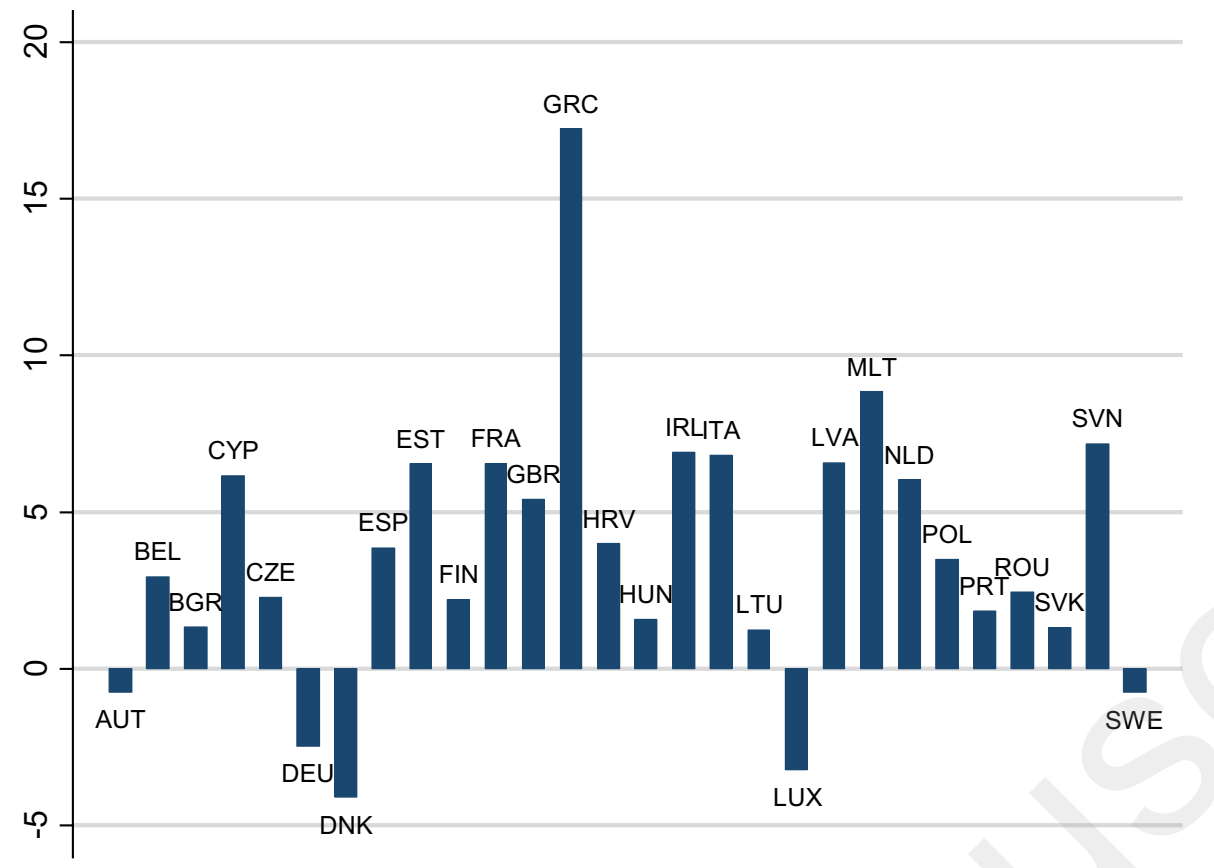

AUT: Austria, BEL: Belgium, BGR: Bulgaria, CYP: Cyprus, CZE: Czech Republic, DNK : Denmark, EST : Estonia, FIN : Finland, FRA: France, DEU: Germany, GRC: Greece, HUN: Hungary, IRL: Ireland, ITA: Italy, LVA: Latvia, LTU : Lithuania, LUX: Luxembourg, MLT :Malta, NLD : Netherlands, POL : Poland, PRT :Portugal, ROU: Romania, SVK: Slovakia, SVN: Slovenia, ESP: Spain, SWE: Sweden, GBR: United Kingdom

Fig. 3 Effective marginal tax rate of environmental taxation (mean over the period 2005-2017)

Among the explanatory variables, the Pigouvian hypothesis calls for examining two complementary measures of ET. The first one represents the revenue of environmental taxes (labeled ET_REV). It is measured with the ratio of all the environmental tax revenues over total tax revenues. ${ }^{5}$ The second one is a proxy for the effective marginal tax rate of environmental taxation (labeled ET_RATE). As such we use the variation of the implicit energy tax rate calculated over two successive calendar years. ${ }^{6}$ As mentioned in the introduction, if ET_RATE is used in the Pigouvian way and proves effective at reducing GHG emissions, we should observe a negative correlation between ET_RATE and GHG emissions, which should reduce the tax base for the ETs. If instead ET are inefficient at correcting the externality, even in the case when governments acted in a Pigouvian way, the externality would still remain and the revenue source with it. In this case we should observe both high ET rates and revenues. We hence estimate the model using both ET_RATE and ET_REV as proxies for the country's environmental fiscal effort. We hold that the

\footnotetext{
5 According to Eurostat, our data source, “... an environmental tax is a tax whose base is a physical unit (or a proxy of a physical unit) of something that has a proven, specific negative impact on the environment". Hence environmental taxes fall within the following economic sectors: energy, transport, pollution, resources. Eurostat data are compatible with the concepts used in the system of national accounts. Throughout the paper, we stick to this definition and to this source of official data.

${ }^{6}$ The implicit energy tax rate is measured as the ratio of energy tax revenues to final energy consumption. Energy tax revenues are calculated in constant price euros (deflated with the implicit GDP deflator, prices of year 2010) and final energy consumption is assessed in tons of oil equivalent. Eurostat is the source for these data.
} 
Pigouvian hypothesis is confirmed if: a) in countries with a positive relative difference between the GHG target and the observed emissions, there is a positive correlation between GHG_DIFF and ET_RATE; that because higher tax rates further reduce the emissions and thus increase the positive difference between the target and the observed value of GHG; furthermore GHG_DIFF and ET_REV should be not significantly correlated; b) in countries where instead there is a negative difference between the GHG target and the observed emissions, again a positive correlation is found between GHG_DIFF and ET_RATE, because higher tax rates reduce the emissions and therefore reduce the negative difference between the target and the observed value of GHG; once more a not significant correlation should exist between GHG_DIFF and ET_REV.

Among the economic variables of vector $\mathbf{X}$ we begin by examining the complex relationship between income-related variables and pollution. A first theoretical linkage is the well-known "environmental Kutznets curve"; this hypothesis posits a positive relationship between economic development and environmental degradation at low levels of per capita income, which then turns negative when citizens-taxpayers' support for environmental protection begins to improve environmental quality, including the reduction of GHG emissions. In the context of our sample of highly developed countries, most observations should be paced in the negatively sloped portion of the curve. More recently, however, Ordás Criado et al. (2011) provide a partially observational equivalent explanation of the relationship between income and environmental protection. In the context of neoclassical growth models, they show that, along the pollution optimal path, the growth rate of output per capita has a negative impact on the growth rate of emissions per capita (scale effect), which is in turn negatively related with the initial level of pollution (defensive effect). In the extended version of their model, the impact of the initial level of output per capita is not a priori defined. Their contribution requires considering not only a measure of per capita income growth (which would be sufficient to test the environmental Kutznets curve hypothesis) but also the initial level of per capita income as a control. We then insert in Eq. (1) both indicators of per capita economic growth (G_GDPPC) and of per capita income levels (GDPPC) in logarithm, and let the sign be determined by the empirical analysis.

Vector $\mathbf{W}$ includes controls for energy and environmental policies. We control for the energy intensity in production (variable ENERGY_INT), specified as the kilogram of oil equivalent per 1000 euros worth of products. The expected sign on this covariate is always negative, since in countries with a positive difference higher values of ENERGY_INT increase GHG emissions, thus reducing the value of $\mathrm{GHG}_{-}$ DIFF; in countries with a negative difference, instead, more pollution increases the negative GHG_DIFF, resulting again in an inverse correlation. We also include a linear TREND, which captures the increasing diffusion of environmental regulations over time in our sample (Botta and Kozluk 2014).

Variables in vector $\mathbf{Z}$ characterize the transmission mechanism of the environmental taxation. To capture the opposite visions of government that the welfare economics and the public choice traditions propose, we include two control 
variables. The first is RLE, an indicator of the degree of enforcement of the law in the country, from the World Bank World Governance Indicators. Greater values of RLE suggest that government decisions are more efficiently implemented, which minimizes government discretion that would instead be magnified in a Leviathan world ${ }^{7}$. Conversely, a Leviathan-type government should be privy to special interest groups that stand against environmental regulation; we proxy this possible effect through the variable VA_INDUS, i.e., the share of value added from industry on total GDP. This variable is commonly used in the literature (Fredriksson 2014; Cadoret and Padovano 2018) and reflects the idea that the greater is the value added of an industry, the higher are the producers' costs of coordination in order to get organized as a lobby. The predicted impact of VA_IND on GHG_DIFF is therefore positive, since more value added increases lobbying costs, which reduces observed GHG thus increasing the positive difference (or increases the negative one).

In a Pigouvian world a statistically not significant coefficient would suggest that these pressures have no impact on governments' tax decisions; a positive and significant coefficient, instead, would capture the effect that the size of the industry exerts on environmental taxation.

\subsection{Sample}

The sample encompasses 28 countries that, through Decision 406/2009, have (a) committed themselves to collectively reduce GHG to $70 \%$ of their 1990 levels by the year 2020; and (b) agreed to a series of country-specific targets, to account for the economic and environmental starting points of each country, especially the former Eastern European ones (Benjamin et al. 2015). These countries are Austria, Belgium, Bulgaria, Cyprus, Croatia, Czech Republic, Denmark, Estonia, Finland, France, Germany, Greece, Hungary, Ireland, Italy, Latvia, Lithuania, Luxembourg, Malta, the Netherlands, Poland, Portugal, Romania, Slovakia, Slovenia, Spain, Sweden and the United Kingdom. The time interval covers the period 2005-2017, for which Eurostat provides coherent data for the Greenhouse gas emissions in Effort Sharing Decision (ESD) sectors; furthermore, 2005 is the beginning year for the effort sharing policy in the attainment of the GHG target. Each variable thus features a maximum of $13 \times 28=364$ observations, quite enough to obtain efficient estimates. Table 1 provides the descriptive statistics, while Table in the "Appendix" reassumes the characteristics of the variables and their data sources.

Tables 2, 3 and 4 present the results that are pertinent to the objective of our analysis. We test all the control variables described in 2.2 and keep the significant ones.

\footnotetext{
${ }^{7}$ We have also tried alternative variables, such as the World Bank measure of regulatory quality and of control of corruption. The results do not change qualitatively at all, since all these indicators are highly correlated. We choose the measure of the rule of law because of its broader scope. The estimates with the alternative indicators are available upon request.
} 
Table 1 Descriptive Statistics

\begin{tabular}{llcccc}
\hline Variables & $(1)$ & $\begin{array}{l}(2) \\
\text { mean }\end{array}$ & $\begin{array}{l}\text { (3) } \\
\text { sd }\end{array}$ & $\begin{array}{l}\text { (4) } \\
\text { min }\end{array}$ & $\begin{array}{l}(5) \\
\text { max }\end{array}$ \\
\hline GHG_DIFF & 364 & 0.0694 & 0.167 & -0.195 & 0.707 \\
D_ET_RATE & 364 & 3.618 & 14.79 & -49.79 & 83.35 \\
ET_REV & 364 & 7.263 & 1.692 & 4.150 & 11.63 \\
G_GDP_PC & 364 & 1.728 & 3.920 & -14.56 & 23.94 \\
DEBT & 364 & 60.48 & 34.70 & 3.700 & 178.9 \\
logGDP_PC & 364 & 10.37 & 0.371 & 9.427 & 11.49 \\
logENERGY_INT & 364 & 4.980 & 0.285 & 4.039 & 5.717 \\
ET_RATE & 364 & 41.068 & 13.174 & 15 & 62.28 \\
RLE & 364 & 1.134 & 0.611 & -0.138 & 2.100 \\
VA_INDUS & 364 & 23.46 & 5.868 & 9.368 & 38.52 \\
SC_EXP & 364 & 16.40 & 3.906 & 7.900 & 25.60 \\
GS_EXP & 364 & 6.393 & 1.897 & 2.800 & 12.90 \\
\hline
\end{tabular}

\section{Pigouvian or Leviathan taxes?}

\subsection{Testing the Pigouvian hypothesis}

The estimates of equation (1) are reported in Table 2, which shows the estimation results for the whole sample of 26 countries (model 1-3), for countries with a negative GHG_DIFF values (model 4, i.e., those that have still to attain the target, mainly the western Europeans ones) and for those with a positive value of GHG_DIFF (model 5, i.e., the countries that have already attained the target, mainly the western Europeans ones).

Our estimates appear consistent with the Pigouvian hypothesis: ET_REV is negative and not statistically significant, whereas ET_RATE has the expected positive sign. This pattern of results confirms that high marginal rates on ET actually reduce the environmental externality represented by the GHG emissions and the tax base for ET with it. The positive and significant coefficient of ET_RATE in both subsamples is consistent with the Pigouvian hypothesis; its impact is quantitatively similar in both Eastern European countries, which have already achieved their targets, and in Western European ones, which still have to attain it. The Arellano-Bond estimation technique here accounts for the potential endogeneity of ET_REV; yet, since its coefficient is not statistically significant, this does not affect the validity of the estimates.

Coming to the economic controls, we observe that faster economic growth reduces the distance from the target, consistently with the theory of the environmental Kutznets curve; this effect is especially evident in countries with a positive distance from the target, i.e., mainly the Eastern European ones, characterized by rates of economic expansion above the sample average. Higher levels of GDP per capita instead seem to raise GHG emissions, thereby reducing the distance from the target in both the short and in the long run, regardless of the country's position 


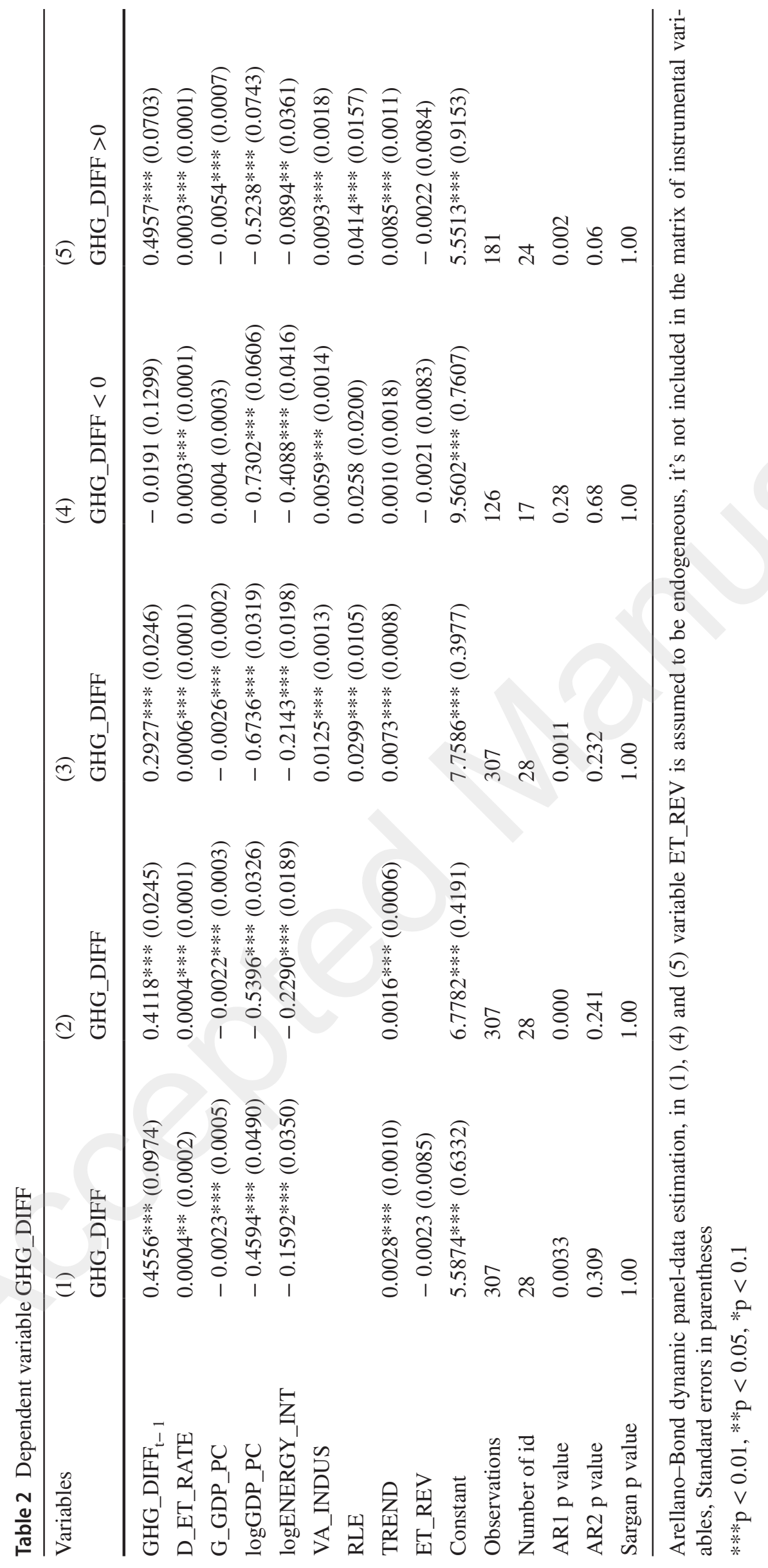


with respect to the target. Among the energy/environmental variables of vector $\mathbf{W}$, the estimates confirm the expected negative relationship between energy intensity of production and the dependent variable, as well the expected positive relationship between the trend and the dependent variable. Specifically, in countries with a positive difference, higher values of ENERGY_INT reflect higher GHG emissions, which reduce the value of GHG_DIFF; in countries with a negative difference instead more emissions increase the negative GHG_DIFF, resulting again in a negative correlation. As it is logic to expect, the negative impact of high energy intensity is stronger in countries that still have to attain their target. The trend has a positive coefficient throughout the sample, but it is again stronger in countries with a positive coefficient. To the extent that this variable captures the diffusion of regulation, this result suggests that command and control measures are less effective at reducing GHG emissions than Pigouvian taxes.

Among the variables of the political vector $\mathbf{Z}$, in all the specifications, the coefficient on the industry's value added is positive and significant. This sign is not consistent with the Leviathan hypothesis, since under this type of governments industrial lobbies should be able to obtain fewer (or less stringent) constraints on their polluting activities, resulting in a smaller difference between the targeted and the observed values of GHG emissions (Cadoret and Padovano 2018). Conversely, in a Pigouvian environment, a positive and significant coefficient on VA_INDUS suggests that polluting industries are taxed more, pollute less, which increases the distance between the targeted and the observed values of GHG emissions. The positive coefficients on the proxy for the rule of law too corroborates this interpretation; once more, this coefficient is larger in the with a positive difference, i.e., the Western European ones.

\subsection{Testing the Leviathan hypothesis}

There are two possible approaches to test the Leviathan hypothesis. One is a contrario; in other words, given the stark differences between the implications of the Pigouvian and the Leviathan hypothesis, the empirical support for the former can be taken as falsification of the latter. We take an alternative route and try to make a step further in the analysis, by proposing a direct test of the Leviathan hypothesis. In this respect, our empirical strategy exploits the fact that Leviathan governments maximize revenues to secure their power base and attempt to do so at the lowest political cost. ET lends itself well to these political maneuvers, as ET are known to be the least unpopular of all taxes (EU Commission 2014) because of voters' positive outlook on protecting the environment. Furthermore, in order to secure a power structure the Leviathan should channel the ET revenues to redistributive expenditures, which can target specific groups, thus yielding higher political returns, as opposed to general purpose, public-good like expenditure items, which benefit the population at large in a rather undifferentiated manner.

We therefore regress two quite opposite types of expenditure items, social expenditures SC_EXP (as classified by Eurostat) and expenditures for general services GS_EXP on ET revenues and the same vector of controls as in Eq. (1). Both are 


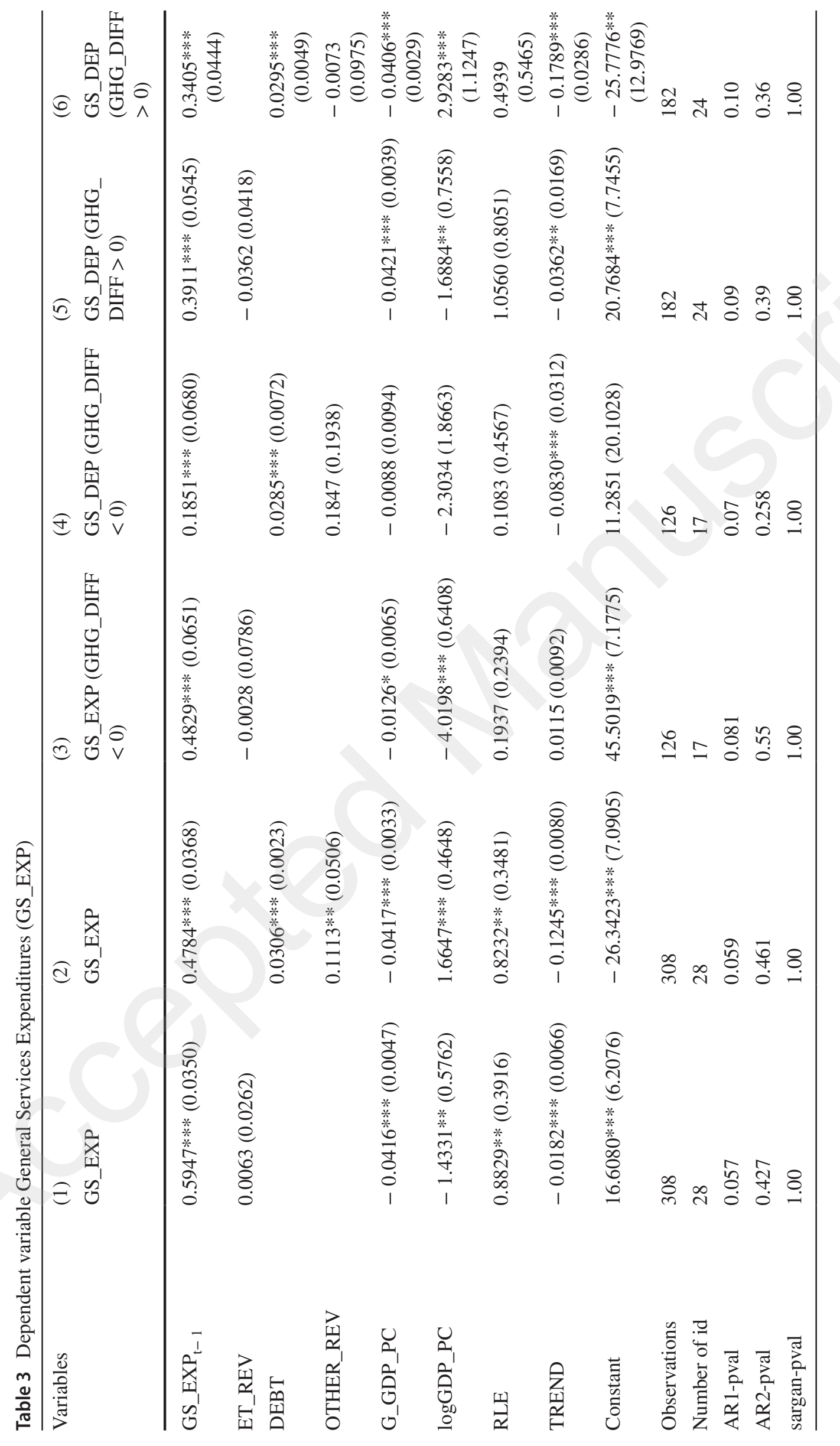


Table 4 Dependent variable SC_EXP

\begin{tabular}{|c|c|c|c|c|c|c|}
\hline Variables & $\begin{array}{l}(1) \\
\text { SC_EXP }\end{array}$ & $\begin{array}{l}(2) \\
\text { SC_EXP }\end{array}$ & $\begin{array}{l}(3) \\
\text { SC_EXP } \\
(\text { GHG_DIFF } \\
<0)\end{array}$ & $\begin{array}{l}(4) \\
\text { SC_EXP } \\
\left(\mathrm{GHG}_{-}\right. \\
\mathrm{DIFF}<0)\end{array}$ & $\begin{array}{l}(5) \\
\text { SC_EXP } \\
(\mathrm{GHG} \text { _DIFF } \\
>0)\end{array}$ & $\begin{array}{l}(6) \\
\text { SC_EXP } \\
\left(G H G \_D I F F\right. \\
>0)\end{array}$ \\
\hline$S_{C} \mathrm{EXP}_{\mathrm{t}-1}$ & $\begin{array}{r}0.5679 * * * \\
(0.0511)\end{array}$ & $\begin{array}{r}0.6180 * * * \\
(0.0460)\end{array}$ & $\begin{array}{r}0.6784 * * * \\
(0.0726)\end{array}$ & $\begin{array}{r}0.6594 * * * \\
(0.0884)\end{array}$ & $\begin{array}{r}0.5897 * * * \\
(0.0451)\end{array}$ & $\begin{array}{r}0.5480 * * * \\
(0.0394)\end{array}$ \\
\hline ET_REV & $\begin{array}{l}0.0686 \\
\quad(0.0462)\end{array}$ & & $\begin{array}{l}0.0487 \\
\quad(0.1563)\end{array}$ & & $\begin{array}{r}-0.0430 \\
(0.0546)\end{array}$ & \\
\hline DEBT & & $\begin{array}{r}-0.0034 \\
(0.0055)\end{array}$ & & $\begin{array}{r}-0.0119 \\
(0.0077)\end{array}$ & & $\begin{array}{l}0.0016 \\
\quad(0.0101)\end{array}$ \\
\hline $\begin{array}{c}\text { OTHER_ } \\
\text { REV }\end{array}$ & & $\begin{array}{r}-0.0087 \\
(0.0649)\end{array}$ & & $\begin{array}{r}-0.1691 \\
(0.2604)\end{array}$ & & $\begin{array}{r}-0.0601 \\
(0.0865)\end{array}$ \\
\hline G_GDP_PC & $\begin{array}{c}-0.1630 * * * \\
(0.0099)\end{array}$ & $\begin{array}{c}-0.1661 * * * \\
(0.0060)\end{array}$ & $\begin{array}{c}-0.1850 * * * \\
(0.0181)\end{array}$ & $\begin{array}{c}-0.1719 * * * \\
(0.0158)\end{array}$ & $\begin{array}{c}-0.1551 * * * \\
(0.0041)\end{array}$ & $\begin{array}{c}-0.1496 * * * \\
(0.0071)\end{array}$ \\
\hline logGDP_PC & $\begin{array}{c}-4.9498 * * * \\
(1.7341)\end{array}$ & $\begin{array}{c}-3.5733 * * * \\
(0.6515)\end{array}$ & $\begin{array}{r}-4.6653^{*} \\
(2.7882)\end{array}$ & $\begin{array}{c}-8.0887 * * * \\
(2.8227)\end{array}$ & $\begin{array}{c}-1.9339 * * * \\
(0.6562)\end{array}$ & $\begin{array}{r}-1.8281 \\
(1.1423)\end{array}$ \\
\hline RLE & $\begin{array}{l}0.3937 * * \\
(0.1884)\end{array}$ & $\begin{array}{l}0.4589 \\
\quad(0.4430)\end{array}$ & $\begin{array}{l}0.2370 \\
\quad(0.3074)\end{array}$ & $\begin{array}{r}-0.1799 \\
(0.7152)\end{array}$ & $\begin{array}{l}0.6643 * \\
(0.3732)\end{array}$ & $\begin{array}{l}0.1877 \\
\quad(0.5402)\end{array}$ \\
\hline TREND & $\begin{array}{r}0.0765 * * * \\
(0.0220)\end{array}$ & $\begin{array}{r}0.0616 * * * \\
(0.0173)\end{array}$ & $\begin{array}{l}0.0887 * * \\
(0.0348)\end{array}$ & $\begin{array}{r}0.1462 * * * \\
(0.0450)\end{array}$ & $\begin{array}{r}0.0341 * * * \\
(0.0098)\end{array}$ & $\begin{array}{l}0.0005 \\
\quad(0.0454)\end{array}$ \\
\hline Constant & $\begin{array}{c}57.3412 * * * \\
(18.5761)\end{array}$ & $\begin{array}{c}43.5777 * * * \\
(5.9375)\end{array}$ & $\begin{array}{l}54.4994^{*} \\
(31.5573)\end{array}$ & $\begin{array}{c}108.4456 * * * \\
(41.3246)\end{array}$ & $\begin{array}{c}25.9914 * * * \\
(6.8856)\end{array}$ & $\begin{array}{r}31.1422 * * \\
(15.0032)\end{array}$ \\
\hline $\begin{array}{l}\text { Observa- } \\
\text { tions }\end{array}$ & 308 & 308 & 126 & 126 & 182 & 182 \\
\hline $\begin{array}{c}\text { Number } \\
\text { of id }\end{array}$ & 28 & 28 & 17 & 17 & 24 & 24 \\
\hline AR1-pval & 0.0057 & 0.001 & 0.31 & 0.06 & 0.00 & 0.06 \\
\hline AR2-pval & 0.015 & 0.012 & 0.05 & 0.02 & 0.43 & 0.29 \\
\hline sargan-pval & 1.00 & 1.00 & 1.00 & 1.00 & 1.00 & 1.00 \\
\hline
\end{tabular}

normalized by GDP. According to the Eurostat classification itself, social protection expenditures are the ones with the strongest redistributive profile, while general services are the closest to the concept of public goods. The stark difference between these expenditure items maximizes the power of our test which, admittedly, because of the rather low share of ET over total revenues, remains rather low. Nevertheless, to confirm the Leviathan hypothesis, we should find a positive correlation between ET_REV and SC_EXP, but not with GS_EXP. A lack of statistical significance on the coefficients of ET_REV on both expenditure items is consistent with the implication of the Pigouvian hypothesis that ET are sufficient to correct the externality, and revenues should not be targeted to any specific expenditure. Using once more an Arellano-Bond technique, we estimate the following model:

$$
\mathbf{Y}_{i t}=\alpha_{1} \mathbf{Y}_{i t-1}+\beta_{1} \mathbf{E T} \_\mathbf{R E V} \mathbf{V}_{\mathrm{it}}+\gamma_{1} \mathbf{X}_{i t}+\delta_{1} \mathbf{W}_{i t}+\theta_{1} \mathbf{Z}_{i t}+\varphi_{i}+\eta_{i t}
$$

where vector $\mathbf{Y}_{i t}$ includes SC_EXP, but not with GS_EXP. Table 3 reports the results for general services expenditures, while table 4 illustrates the estimates for social protection. None of the estimates, conducted on the whole sample of countries and 
other the subgroups of under- and over-achievers with respect to the GHG target, ever reveal a statistically significant coefficient on ET_REV; this result further confirms the Pigouvian hypothesis and disproves the Leviathan one.

\section{Conclusions}

Examining how governments use ET is a difficult task, especially in terms of finding a proper empirical strategy; our one has the important advantage of minimizing the discretionary intervention of the analyst in evaluating the countries' commitment in achieving environmental goals, since we focus on a clearly measurable environmental goal, the reduction of GHG emission, which the EU-27 countries themselves have formally decided to attain. Hence, and with no claim of having provided conclusive and/or general evidence, our interpretation of the overall results of the analysis is that environmental taxation is mainly conducted in a Pigouvian way and that it is efficient at correcting the environmental externality. The test of the theoretically opposite Leviathan hypothesis instead shows no support from the data.

The positive correlation between ET rates and distance from the target, together with the negative statistical significance on environmental tax revenues suggests that high Pigouvian tax rates reduce the environmental externality represented by GHG emissions and therefore shrink the tax base for these taxes. Both countries that have already attained their GHG emissions targets and those that still have to meet it are characterized by similar levels of correlation between ET rates and reduction of GHG emissions. This suggests that environmental policies tend to become embedded in the fiscal system even after certain policy goals are reached.

\section{Compliance with ethical standards}

Conflict of interest On behalf of all authors, the corresponding author states that there is no conflict of interest.

\section{Appendix}

\begin{tabular}{lll}
\hline Name & Definition & Source \\
\hline GHG & $\begin{array}{l}\text { Greenhouse gas emissions in Effort Sharing Decision (ESD) sec- } \\
\text { tors—-million tonnes } \mathrm{CO}_{2} \text { equivalent }\end{array}$ & Eurostat \\
Target & $\begin{array}{l}\text { DÉCISION (UE) 2017/1471 de la Commission du 10 août 2017 } \\
\text { modifiant la décision 2013/162/UE afin de réviser les allocations }\end{array}$ & \\
& $\begin{array}{l}\text { annuelles de quotas d'émission des États membres pour la péri- } \\
\text { ode 2017-2020 [notifiée sous le numéro C (2017) 5556] }\end{array}$ & \\
& (Target - GHG observed)/GHG observed & Calculated \\
GHG_DIFF & Total environmental taxes as Percentage of total revenues from & Eurostat \\
ET_REV & taxes and social contributions (including imputed social contribu- & \\
& tions) & \\
\hline
\end{tabular}




\begin{tabular}{|c|c|c|}
\hline Name & Definition & Source \\
\hline ET_REV_GDP & Total environmental taxes as Percentage of GDP & Eurostat \\
\hline ET_RATE & $\begin{array}{l}\text { This indicator is defined as the ratio between energy tax revenues } \\
\text { and final energy consumption calculated for a calendar year. } \\
\text { Energy tax revenues are measured in euro } 2010 \text { (deflated with } \\
\text { the gross market produck implicit deflator) and the final energy } \\
\text { consumption in TOE (tonnes of oil equivalent), therefore the ITR } \\
\text { on energy is measured in EUR per TOE. }\end{array}$ & Eurostat \\
\hline D_ET_RATE & Variation of ET_RATE & \\
\hline DEBT & Government consolidated gross debt as percentage of GDP & Eurostat \\
\hline ENERGY_INT & $\begin{array}{l}\text { Energy intensity of GDP in purchasing power standards (PPS), } \\
\text { Kilograms of oil equivalent (KGOE) per thousand euro in pur- } \\
\text { chasing power standards (PPS) }\end{array}$ & Eurostat \\
\hline G_GDP_PC & $\begin{array}{l}\text { GDP per capita growth (annual \%), aggregates are based on con- } \\
\text { stant } 2010 \text { U.S. dollars. GDP per capita }\end{array}$ & World Bank WDI \\
\hline GDP_PC & GDP per capita, PPP (constant 2011 international \$) & World Bank WDI \\
\hline RLE & Rule of law & World Bank WGI \\
\hline VA_INDUS & Industry, value added (\% of GDP) & World Bank WDI \\
\hline GS_EXP & $\begin{array}{l}\text { Total general government expenditure for general public services as } \\
\text { a percentage of GDP }\end{array}$ & Eurostat \\
\hline SC_EXP & $\begin{array}{l}\text { Total general government expenditure for social protection as a } \\
\text { percentage of GDP }\end{array}$ & Eurostat \\
\hline
\end{tabular}

\section{References}

Baumol, W. J., \& Oates, W. E. (1988). The Theory of Environmental Policies. Cambridge: Cambridge University Press.

Benjamin, C., Cadoret, I., \& Hubert, M. H. (2015). The European climate policy is ambitious: Myth or reality? Revue d'Economie Politique, 125, 731-775.

Botta, E., \& Kozluk, T. (2014). Measuring environmental policy stringency in OECD countries: A composite index approach, OECD Economics Department Working Papers No 1177.

Cadoret, I., \& Padovano, F. (2018). Exploring the determinants and consequences of the stringency of environmental policies. Center Condorcet Working papers, 2018-6ccr.

Cadoret, I., \& Padovano, F. (2016). The political drivers of renewable energies policies. Energy Economics, 56, 261-269.

Chang, T. H., Huang, C. M., \& Lee, M. C. (2009). Threshold effect of the economic growth rate on the renewable energy development from a change in energy price: Evidence from OECD countries. Energy Policy, 37, 5796-5802.

Chang, C., \& Berdiev, A. (2011). The political economy of energy regulation in OECD countries. Energy Economics, 33, 816-825.

Conconi, P. (2003). Green lobbies and transboundary pollution in large open economies. Journal of International Economics, 59, 399-422.

Congleton, R. (1992). Political institutions and pollution control. The Review of Economics and Statistics, 74, 412-421.

Decision n. 406/2009 of the EU parliament and of the Council of Ministries, Journal officiel de l'Union Europeenne 5 juin 2009.

European Commission. (2014). Special Eurobarometer 416. Attitudes of European citizens towards the environment. Bruxelles, European Union.

Kirchgassner, G., \& Schneider, F. (2003). On the political economy of environmental policy. Public Choice, 115, 369-396. 
OECD. (2011). Environmental taxation a guide for policy makers. Paris: OECD.

Ordás Criado, C., Valente, S., \& Stengos, T. (2011). Growth and pollution convergence: Theory and evidence. Journal of Environmental Economics and Management, 62, 199-214.

379 Sandmo, A. (2010). The Scale and Scope of Environmental Taxation. NHH Dept. of Economics Discus380 sion Paper n. 18/2009.

381 Schöb, R. (2003). The double dividend hypothesis of environmental taxation. A survey. Cesifo working 382 papers series $\mathrm{n} .946$.

Tullock, G. (1967). Excess benefit. Water Resources Research, 3, 643-644.

Publisher's Note Springer Nature remains neutral with regard to jurisdictional claims in published maps and institutional affiliations. 